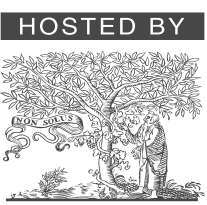

Short communication

\title{
Renal failure and acute coronary syndrome due to use of Cannabis in a 26-year-old young male: A case report
}

\author{
Turgut Karabag a,*, Burcu Ozturk ${ }^{\mathrm{b}}$, Seda Guven ${ }^{\mathrm{b}}$, Nurettin Coskun ${ }^{\mathrm{b}}$, Erkan Ilhan ${ }^{\mathrm{a}}$, Nihan Turhan Caglar ${ }^{\mathrm{a}}$ \\ a Istanbul Training and Research Hospital, Department of Cardiology, Istanbul, Turkey \\ ${ }^{\mathrm{b}}$ Istanbul Training and Research Hospital, Department of Internal Medicine, Istanbul, Turkey
}

\section{A R T I C L E I N F O}

\section{Article history:}

Received 17 August 2015

Accepted 10 November 2015

Available online 18 November 2015

\section{Keywords:}

Cannabis

Acute coronary syndrome

Renal failure

\section{Introduction}

The chemical substance cannabis, which is produced from the leaves of the plant Cannabis sativa, is commonly used by youth in Europe and in our country. ${ }^{1}$ Although heroin, ecstasy, and cocaine have been known to be associated with adverse health effects, there is a common belief in society that cannabis is a relatively benign substance, just like alcohol and tobacco. In addition to its pleasure-inducing actions, C. sativa has also some side effects in various organ systems, particularly the cardiovascular system, and may sometimes threaten life. ${ }^{2}$ In this paper, we reported a 26-year-old male patient presenting to emergency department with acute coronary syndrome and acute renal failure, who had used various forms of cannabis for a long time and had a number cardiovascular risk factors. The mechanism of action of cannabis was also discussed herein.

\section{Case report}

A 26-year-old male with no known chronic disease presented to the emergency department with exertional dyspnea and chest pain. He stated that his complaints had been recurring for 4-5 months but they had recently increased in severity and frequency. He had been smoking for 15 years and using illicit drugs for 12 years. Questioning about his

\footnotetext{
* Corresponding author at: İstanbul Eğitim Araștırma Hastanesi, Koroner Yoğun Bakım Unitesi, Samatya-Fatih, İstanbul, Turkey. Tel.: +90 542 3233425; fax: +90 2124596198. E-mail address: turgutkarabag@yahoo.com (T. Karabag).

Peer review under responsibility of The Society of Cardiovascular Academy.
}

medical history revealed no acute rheumatic fever or glomerulonephritis in the past. His family was free of coronary artery disease and the patient was not taking any medications on a regular basis. He admitted that he had used marijuana for 6 years, kubar (a substance preparation produced by pulverizing leaves and seeds of female $C$. sativa and mixing them with pulverized marijuana) for 4 years, and bonzai (a type of synthetic cannabinoid) for the last 2 years. His blood pressure was $160 / 100 \mathrm{mmHg}$ and his pulse rate was $88 \mathrm{bpm}$. On physical examination, his skin was cold and pale. Cardiovascular examination revealed a 1/6 systolic murmur in aortic focus. Respiratory and other system examinations were normal. An ECG taken in the emergency department was also normal. Creatinine level was $9 \mathrm{mg} / \mathrm{dL}$, urea was $173 \mathrm{mg} / \mathrm{dL}$, and troponin level was $0.5 \mathrm{ng} / \mathrm{dL}$. Troponin elevation was attributed to markedly abnormal renal function and the patient was taken into dialysis via a right femoral catheter. Following dialysis, he again had chest pain, and thus was consulted with the cardiology department. On ECG, there was a $0.5 \mathrm{~mm}$ St segment depression on leads DII, DIII and aVF (Fig. 1). Troponin level was found to be $0.7 \mathrm{ng} / \mathrm{dL}$. Therefore, he was considered to sustain a high-risk unstable angina pectoris and admitted to coronary care unit. Mid and apical septal segments were hypokinetic on echocardiography. His left ventricular diameters increased and ejection fraction was around $50 \%$. He also had mild mitral insufficiency. Clopidogrel $600 \mathrm{mg}$ was loaded along with acetylsalicylic acid $300 \mathrm{mg}$, metoprolol $25 \mathrm{mg}$, enoxaparin $0.4 \mathrm{mg}$, atorvastatin $80 \mathrm{mg}$, and intravenous nitrate infusion. A coronary angiogram was performed, which showed a total occlusion in the right coronary artery (RCA) and a 50\% stenosis with a haziness appearance in left anterior descending artery (LAD) (Fig. 2). Circumflex artery was normal. After balloon angioplasty $80 \%$ diffuse lesion appeared (Fig. 3). A stent was implanted to the RCA with complete vessel opening. LAD lesion was decided to be medically managed. Detailed laboratory tests were done during his intensive care stay. His fasting blood glucose was $76 \mathrm{mg} / \mathrm{dl}$, and the lipid parameters were as follows: total cholesterol $282 \mathrm{mg} / \mathrm{dL}$, LDL-C219 mg/dL, HDL-C $41 \mathrm{mg} / \mathrm{dL}$, and triglyceride $107 \mathrm{mg} / \mathrm{dL}$. Hemoglobin level was 7.9 and anemia was consistent with iron deficiency anemia. The patient underwent a regular dialysis program and was administered 1 unit of erythrocyte suspension. His medical therapy was arranged and he was transferred with a plan to visit the nephrology department for continuation of the dialysis program. A renal biopsy was scheduled but postponed due to fear of bleeding from dual antiplatelet therapy given after percutaneous coronary intervention. At the control examination 2 months after the first admission, he was still on the dialysis program. 


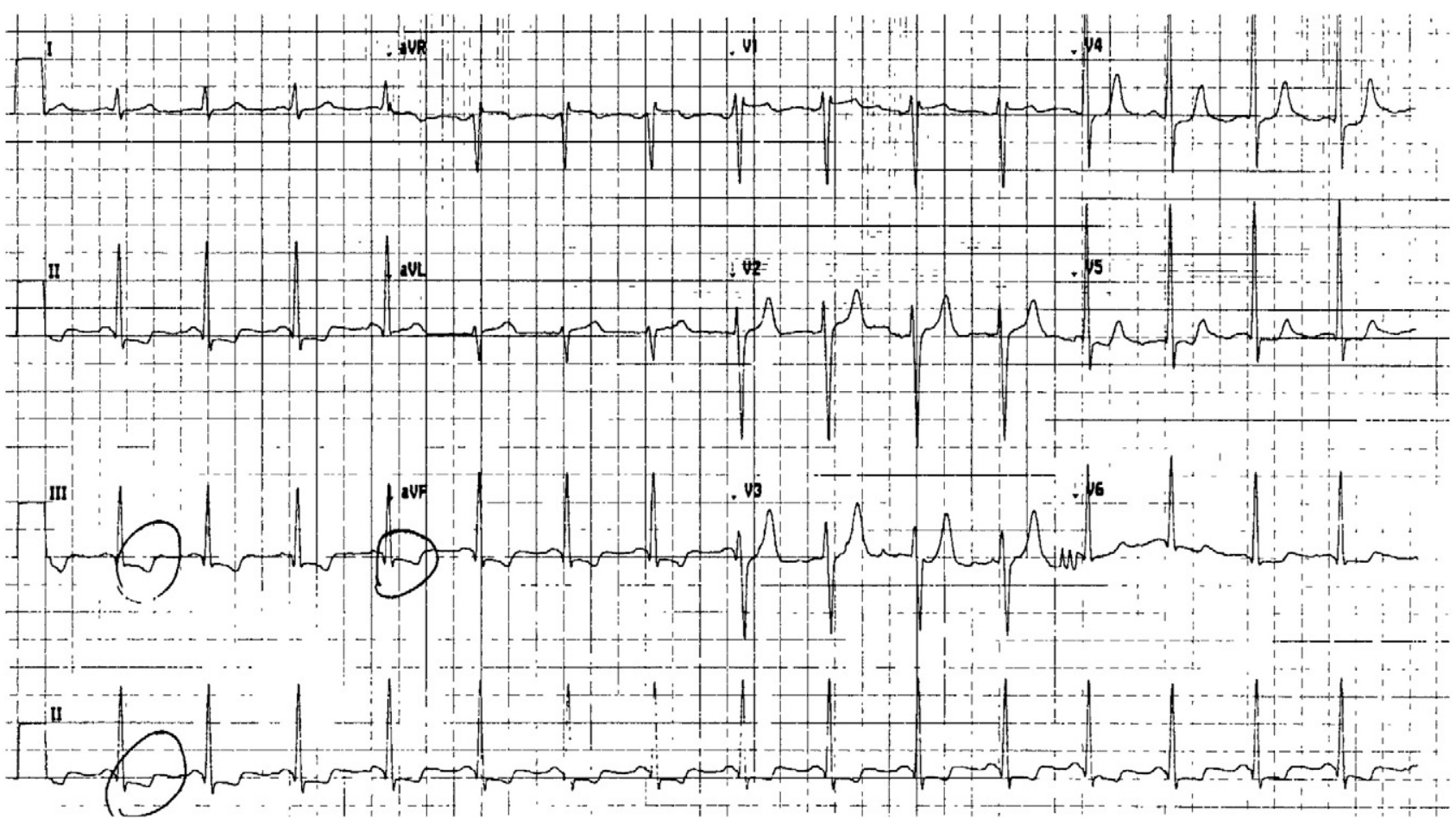

Fig. 1. Figure showing $1 \mathrm{~mm}$ downslopping ST segment depression on leads DII, DIII and aVF.

He had no chest pain or acute ECG changes. He quit using cannabis and smoking. He was on clopidogrel, acetylsalicylic acid, metoprolol, amlodipin, and statin medication.

\section{Discussion}

Cannabis is produced from leaves of the plant $C$. sativa and is known to be the most abused substance in rural and urban centers both in Europe and in our country. It has various preparations worldwide, including marijuana, hash, ganja, kubar, and bonzai. Its main effects are through cannabinoid receptors in the heart, brain, spleen, blood vessels, and immune system. ${ }^{3} \Delta 9$ - tetrahydrocannabinol (THC) is the molecule that is responsible for pharmacological actions of cannabis. THC acutely exerts a vasoconstrictor effect and, additionally, cardiac ischemia as a result of an increase in cardiac workload, and postural hypotension.

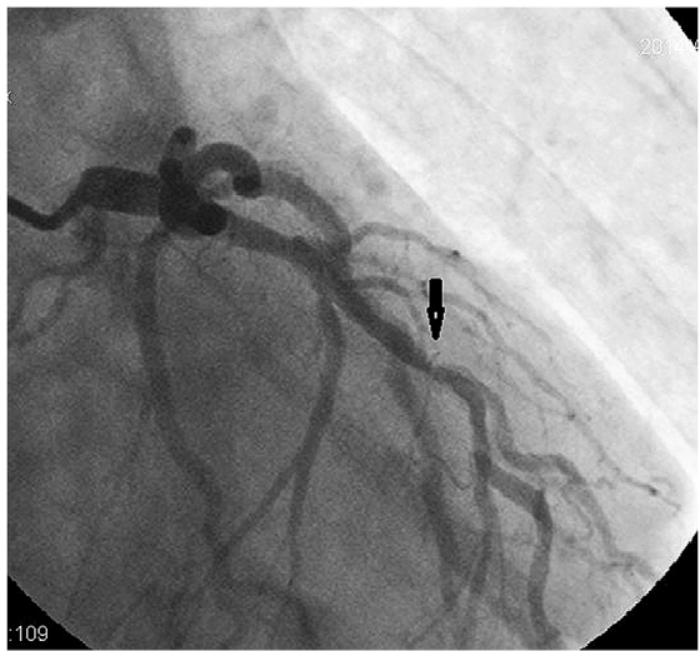

Fig. 2. 50\% stenosis in left anterior descending artery with a hazziness appearance.
Similarly, increased blood carboxyhemoglobin levels are responsible for inadequate myocardial blood supply. In addition, cellular stress resulting from oxidant gasses activates thrombocytes and increases the amount of oxidized LDL and factor VII activity. Thus, it exerts chronic adverse cardiovascular effects by inducing inflammatory responses. ${ }^{4}$ It has also been shown to induce thrombus formation within the coronary artery lumen. ${ }^{4}$ For all these reasons, cannabis has been implicated for the development of coronary artery disease and triggering acute coronary syndromes. ${ }^{4}$ As a result of these marked vascular actions, cannabis-containing cigarettes may worsen angina. ${ }^{5}$ Literature data

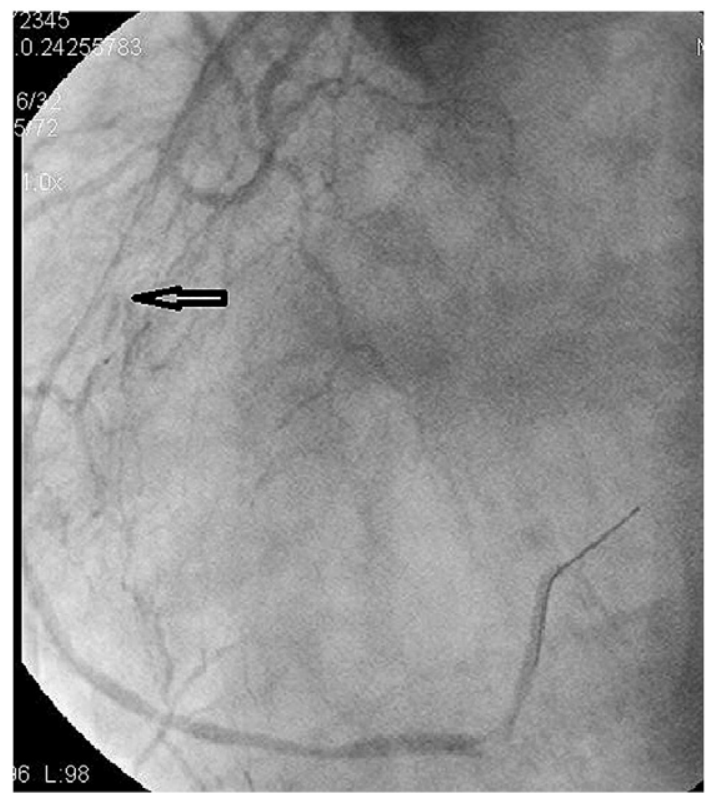

Fig. 3. Figure showing diffuse lesion appeared after baloon angioplasty in right coronary artery. 
suggest that cannabis may trigger acute coronary syndrome in addition to marked sinus tachycardia and frequent premature ventricular depolarizations independent of whether atherosclerotic coronary artery disease is present or not. ${ }^{6}$ Cannabis use can lead to severe cardiovascular events, not only in patients with traditional cardiovascular risk factors, but also in young people without any risk factors. ${ }^{7}$ Our patient had used marijuana for 6 years, kubar for 4 years, and bonzai for 2 years. He presented to our clinic with acute coronary syndrome. We also think that the acute coronary syndrome was a direct result of cannabis consumption earlier that day in our case. It is known that cannabis increases heart rate and blood pressure in low doses, while it lowers the two in higher doses. Although our patient used bonzai on the day of admission, his hemodynamic profile was within normal limits.

Literature data about the renal side effects of cannabis is quite limited. It has been reported that cannabis formulations, especially its intravenous forms, cause transient nonoliguric renal failure. ${ }^{8}$ Bhanushali et al. reported 4 cases of acute renal failure as a result of synthetic cannabinoid use. ${ }^{8}$ Although we could not prove histopathologically, we considered that acute renal failure was chronic. And we think that low hemoglobin count was due to the chronic renal failure. The patient was included in the hemodialysis program and he was on hemodialysis at the latest visits.

There are various researches investigating the relationship between cannabis use and metabolic parameters. Muniyapa et $\mathrm{al}^{9}$ and Berard et $\mathrm{al}^{10}$ found lower HDL cholesterol levels in patients with cannabis abusers compared to the controls. LDL cholesterol levels were similar between cannabis abusers and controls in both of the investigations. In our case, LDL cholesterol levels were higher probably due to the genetic or dietary habits of the patient.

\section{Conclusion}

Cannabis use has been increasing worldwide. Thus, coronary heart disease, acute coronary syndrome, and acute renal failure as a complication of cannabis use are likely to increase in the future. We believe that our case suffered acute coronary syndrome and acute renal failure not only because of conventional atherosclerotic risk factors such as hyperlipidemia and smoking, but also possibly because he had used cannabis for an extended period before admission. Use of cannabis or other illicit drugs should always be questioned in young cases presenting with acute coronary syndrome and/or acute renal failure.

\section{Funding}

None.

\section{Conflict of interest}

No potential conflict of interest relevant to this article was reported.

\section{References}

1. Bachs L, Morland H. Acute cardiovascular fatalities following cannabis use. Forensic Sci Int 2001;124(2-3):200-203.

2. Kocabay G, Yildiz M, Duran NE, Ozkan M. Acute inferior myocardial infarction due to cannabis smoking in a young man. J Cardiovasc Med 2009;10(9):669-670.

3. Joy JE, Watson SJ, Benson JA, editors. Marijuana and medicine: assessing the science base. Washington, DC: National Academy Press; 1999. p. 25-31.

4. Aryana A, Williams MA. Marijuana as a trigger of cardiovascular events: speculation or scientific certainty? Int J Cardiol 2007;118:141-144.

5. Aronow WS, Cassidy J. Effect of smoking marijuana and of a highnicotine cigarette in angina pectoris. Clin Pharmacol Ther 1975;17:549-554.

6. Cappelli F, Lazzeri C, Gensini GF, Valente S. Cannabis: a trigger for acute myocardial infarction? A case report. J Cardiovasc Med (Hagerstown) 2008;9:725-728.

7. Casier I, Vanduynhoven P, Haine S, Vrints C, Jorens PG. Is recent cannabis use associated with acute coronary syndromes? An illustrative case series. Acta Cardiol 2014;69(2):131-136.

8. Bhanushali GK, Jain G, Fatima H, Leisch LJ, Thornley-Brown D. AKI associated with synthetic cannabinoids: a case series. Clin J Am Soc Nephrol 2013;8(4):523-526.

9. Muniyappa R, Sable S, Ouwerkerk R, et al. Metabolic effects of chronic cannabis smoking. Diabetes Care 2013;36:2415-2422.

10. Bérard AM, Bedel A, Le Trequesser R, et al. Novel risk factors for premature peripheral arterial occlusive disease in non-diabetic patients: a case control study. PLoS One 2015;8(3):e37882http://dx.doi.org/10.1371/journal.pone.0037882 [Epub 2013 Mar 22]. 